\title{
The Effect of Gamma-Hydroxybutyric Acid on Naloxone-Precipitated Opiate Withdrawal
}

Marc I. Rosen, M.D., H. Rowland Pearsall, M.D., Scott W. Woods, M.D., and Thomas R. Kosten, M.D.

Because gamma-hydroxybutyric acid (GHB), a GABA metabolite, attenuated spontaneous opiate withdrawal in a prior study, we studied GHB's effect on naloxoneprecipitated opiate withdrawal. Eight opiate-dependent inpatients were stabilized on the opioid levorphanol, $18 \mathrm{mg}$ daily. After an initial acclimatization challenge, subjects underwent three double-blind challenges on consecutive days. Pretreatment in a balanced randomization was with either placebo, GHB, $15 \mathrm{mg} / \mathrm{kg}$, or $\mathrm{GHB}, 30 \mathrm{mg} / \mathrm{kg}$, followed an hour later by intravenous naloxone, $0.4 \mathrm{mg} / 70 \mathrm{~kg}$. GHB produced no significant attenuation of multiple withdrawal measures except for hot-cold feelings. GHB pretreatment slightly accelerated respiration prior to naloxone. Differences with prior studies may be due to (1) timing of GHB administration (giving postwithdrawal in prior studies), (2) direct reversal of GHB's anti-withdrawal effects by naloxone, or (3) differences between naloxoneprecipitated and spontaneous opiate withdrawal. [Neuropsychopharmacology 14:187-193, 1996]
KEY WORDS: Gamma-hydroxybutyric acid; Opiate; Withdrawal; Naloxone; Detoxification

Clonidine's utility in opiate detoxification is limited by side effects including hypotension (Rudd and Blaschke (1985) and lack of efficacy against subjective withdrawal symptoms (Jasinski et al. 1985; Kosten et al. 1985). A new medication, gamma-hydroxybutyric acid (GHB) is an alternative treatment, with the potential advantage over clonidine of a different side effect profile. GHB is an endogenous GABA metabolite found in low concentrations in the human brain (Doherty et al. 1978) and in higher concentrations in other body tissues (Nelson et al. 1981). It has been described as an endogenous neurotransmitter because of the presence of specific highaffinity receptors for GHB and not for GABA (Benavides et al. 1982), the specificity of GHB antagonists

From the Yale University, Department of Psychiatry, New Haven, Connecticut.

Address correspondence to Marc I. Rosen, M.D., Yale University, Department of Psychiatry, 34 Park Street, New Haven, CT 06519.

Received February 1, 1995; revised May 4, 1995; accepted May 11, 1995
(Schmidt et al. 1991), and GHB's presence principally in the synaptosome of cells (Maitre et al. 1983). GHB's effects on other neurotransmitter systems are complex (Snead 1977; Tunnicliff 1992). The dopaminergic effects of GHB and GHB-receptor ligands have been characterized as "neurolepticlike" based on their ability acutely to inhibit dopamine release from striatal slices and their effects on neuroleptic-responsive motor tests (Hechler et al. 1993). Low doses of GHB produce a slight excitation in substantia nigra single-unit recordings, and higher doses produce inhibition (Engberg and Nissbrandt 1993). The combined effect of inhibition of dopamine release and increased dopamine synthesis is thought to lead to an overall increase in striatal dopamine levels (Walters and Roth 1972). GHB is also thought to increase brain acetylcholine (Snead 1977). GABA-B antagonists reverse, and GABA-B agonists mimic the effects of GHB on substantia nigra dopamine neurons (Engberg and Nissbrandt 1993).

In the United States GHB has orphan drug status for the treatment of narcolepsy. It has been piloted for a variety of clinical uses, including anesthesia enhancement (Blumenfeld et al. 1962; Aldrete and Barnes 1968), treatment of Parkinson's disease (Papavasiliou et al. 1973), and 
prevention of relapse to alcohol use (Gallimberti et al. 1989). Therapeutic doses of GHB are well tolerated; nobody from a sample of 48 pilot patients taking GHB to treat narcolepsy discontinued GHB treatment because of side effects (Mamelak et al. 1986). Recently there have been reports of illicit GHB use (Centers for Disease Control 1991; Mack 1993; Wilkinson 1994).

In a preliminary study GHB robustly suppressed signs and symptoms of opiate withdrawal (Gallimberti et al. 1993). Twenty-two heroin dependent and 19 methadone-dependent subjects were hospitalized and then had their opioid discontinued. The withdrawing subjects were then randomized to a single dose of $25 \mathrm{mg} /$ $\mathrm{kg}$ of GHB or placebo, and withdrawal was rated over the ensuing 180 minutes. Within 15 minutes, observerrated withdrawal severity for the GHB group was less than half that of the placebo group. The patients randomized to GHB (total $N=19$ ) were then all successfully detoxified from opiates over an 8-day period using GHB every 2 to 4 hours over the first 2 days and every 4 to 6 hours over the next 6 days.

The current study was designed to determine whether $\mathrm{GHB}$, given prior to naloxone, attenuates the severity of naloxone-precipitated opiate withdrawal. In this study, opioid-dependent subjects on a stable dose of the opioid levorphanol first underwent a double-blind acclimatization challenge, in which they received placebo GHB followed by naloxone, $0.2 \mathrm{mg}$ intravenously. On three consecutive subsequent days, subjects received a randomized sequence of placebo, GHB, $15 \mathrm{mg} / 70 \mathrm{~kg}$, and $\mathrm{GHB}, 30 \mathrm{mg} / 70 \mathrm{~kg}$; 1 hour after GHB administration, subjects received $0.4 \mathrm{mg} / 70 \mathrm{~kg}$ of intravenous naloxone. The eight subjects were block-randomized to each of the six possible GHB sequences, with the two final subjects randomized to an ascending and descending GHB dose sequence.

\section{METHODS}

\section{Subjects}

Eight subjects gave written informed consent and were paid to complete this inpatient study. Two other subjects were enrolled but did not complete all four challenges; the sequences these subjects received were assigned to subsequent subjects. At the conclusion of the study, subjects were detoxified from levorphanol and referred for clinical treatment. Age ranged from 23 to 42 years, and all subjects were male. Six were Caucasian, and two were Hispanic. Subjects were told that the purpose of the study was to determine the effects of GHB on opiate withdrawal. Prior to enrollment, subjects had a screening physical examination and laboratory tests, including complete blood count with differential, thyroid function tests, liver function tests, serum pregnancy tests when appropriate, EKG, urinalysis, urine toxicology testing (EMIT), and serum glucose, electrolyte, BUN, and creatinine levels. Subjects with evidence of serious medical, neurological, or psychiatric illness or of alcohol or sedative dependence were not enrolled.

Screening and admission urine toxicology (EMIT) confirmed opiate abuse in all subjects. Heroin dependence upon hospitalization was defined by a recent history of withdrawal symptoms, at least twice-daily heroin use for the 30 days prior to admission, and withdrawal in response to $0.2 \mathrm{mg}$ of intramuscular naloxone upon admission. Duration of heroin use averaged 7 years (range 3-12 years). All used intravenous heroin, except for one intranasal user. Concurrent drugs of abuse during the 30 days prior to admission were nicotine $(n=7)$, cocaine $(n=3)$, cannabinoids $(n=1)$, and benzodiazepines ( $n=2$; neither subject was dependent).

After verification of opiate dependence with naloxone, subjects were given the orally effective opioid levorphanol at $6 \mathrm{mg}$ three times daily and oxazepam, 30 $\mathrm{mg}$, every 2 hours as needed for residual withdrawal symptoms. Naloxone challenges began after subjects denied any subjective withdrawal for at least 1 day without oxazepam (levorphanol stabilization for 5 to 20 days; mean of 10.5 days).

The level of dependence induced by this levorphanol dose was chosen to be comparable to the level of dependence induced by $25 \mathrm{mg}$ of methadone. These calculations were based on the clinically observed fivefold greater relative analgesic potency of subcutaneous methadone over levorphanol (Jaffe and Martin 1985) and on levorphanol's potency when substituted for maintenance morphine in morphine-dependent subjects (Isbell and Fraser 1953). We have noted somewhat greater subjectrated withdrawal severity after $0.2 \mathrm{mg}$ of intravenous naloxone in subjects stabilized on $25 \mathrm{mg}$ of methadone daily [peak mean approximately 30 on a 100 -point visual analog scale (VAS); Rosen et al. 1995] than in subjects stabilized on this maintenance dose of levorphanol receiving the same naloxone dose (peak mean approximately 20; Rosen et al. in press).

\section{Experimental Procedure}

Subjects fasted after breakfast prior to challenges and were connected to an intravenous line. GHB was administered 2 hours before the subjects' regularly scheduled 3:00 P.M. levorphanol dose. GHB was supplied by the Sigma F and D Division (Saint Louis, MO) in a powder form as the sodium salt (Catabate). It was administered as a $17 \%$ solution in Cherry Syrup (USP), with syrup alone as placebo. Naloxone was infused over a 1-minute period 1 hour later. One hour after naloxone, the subjects received their scheduled levorphanol dose.

Outcome measures of severity included subject-rated withdrawal, observer-rated withdrawal, vital signs, skin 
temperature, and pupil photo size. Subjects rated withdrawal severity on a VAS from 0 to 100 , with anchors at 0 (None), 50 (Average), and 100 (Worst Ever). A single observer, blind to the purpose of the study, completed a 12item, anchored scale of observable withdrawal behaviors, based on the scale of Peachey and Lei (1988). Each of the following 12 items was rated from 0 to 4 : tearing, nasal congestion, yawning, coughing/sneezing, gooseflesh, sweating, tremor, restlessness, nausea/vomiting, muscle ache, diarrhea/cramps, and hot/cold. Counts were made for the preceding 5 minutes of yawns, nasal sniffs, sneezes/coughs, muscle twitches, and muscle stretching. (Scale available from authors upon request). Skin temperature was measured by a thermistor attached to the subjects' index fingertip. Blood pressure and pulse were measured automatically by a vital signs monitor (Dinamapp). The above data were collected at time points (relative to the naloxone administration) of -90 , -65 (prior to GHB administration), $-10,5,10,15,20$, $25,30,40,50$, and 60 minutes; vital signs were assessed at $-75,-20$, and -5 minutes as well. Pupils were photographed by a Polaroid camera with $2 \times$ magnification at $-90,-75,-30,-5,15,30$, and 60 minutes. Pupil photo size was measured by calipers.

\section{DATA ANALYSIS}

Individual withdrawal signs and symptoms were the dependent measures. The acclimatization challenge was omitted. Dependent measures were first summarized as the difference between pre-GHB baseline (mean of values prior to $G H B$ ) and post-GHB values (mean of values post-GHB, prior to naloxone). The area under the curve (AUC) of the change from baseline was then calculated using the trapezoidal method, as a change from the baseline (mean of values prior to $\mathrm{GHB}$ ) to all the post-naloxone time points, divided by 60 minutes. With this method of calculating AUC change/time, dependent measures that represent the sum of counts over the pre-

Table 1. Mean (SEM) AUC Change/Time from Baseline by GHB Condition

\begin{tabular}{|c|c|c|c|c|}
\hline Sign & $\begin{array}{c}\text { Placebo } \\
(n=8)\end{array}$ & $\begin{array}{c}15 \mathrm{mg} \\
(n=7)\end{array}$ & $\begin{array}{c}30 \mathrm{mg} \\
(n=8)\end{array}$ & ANOVA \\
\hline W/D Total & $10.7(1.6)$ & $10.9(1.9)$ & $9.6(1.6)$ & NS \\
\hline Tearing & $1.5(0.3)$ & $1.5(0.3)$ & $1.5(0.2)$ & NS \\
\hline Nasal & $1.7(0.3)$ & $1.6(0.6)$ & $1.7(0.4)$ & NS \\
\hline Nasal count & $2.4(0.8)$ & $2.5(1.3)$ & $2.4(0.7)$ & NS \\
\hline Yawns & $1.8(0.4)$ & $1.7(0.4)$ & $1.5(0.4)$ & NS \\
\hline Yawn count & $2.9(0.8)$ & $2.7(0.7)$ & $2.3(0.7)$ & NS \\
\hline Sneeze & $0.3(0.2)$ & $0.4(0.3)$ & $0.3(0.2)$ & NS \\
\hline Sneeze count & $0.4(0.2)$ & $0.5(0.4)$ & $0.4(0.3)$ & NS \\
\hline Twitch & $0.7(0.3)$ & $1.2(0.5)$ & $0.8(0.3)$ & NS \\
\hline Twitch count & $1.2(0.5)$ & $3.0(1.4)$ & $1.6(0.7)$ & NS \\
\hline Muscle tension & $1.4(0.3)$ & $1.1(0.4)$ & $1.4(0.3)$ & NS \\
\hline Tension count & $1.2(0.5)$ & $.80(0.4)$ & $1.0(0.4)$ & NS \\
\hline Restlessness & $0.8(0.3)$ & $0.6(0.2)$ & $0.4(0.3)$ & NS \\
\hline Nausea & $0.3(0.2)$ & $0.5(0.2)$ & $0.5(0.1)$ & NS \\
\hline Diarrhea/cramps & $0.5(0.2)$ & $0.5(0.2)$ & $0.4(0.1)$ & NS \\
\hline Hot $/$ cold & $1.0(0.2)$ & $0.7(0.2)$ & $0.7(0.1)$ & Significant ${ }^{a}$ \\
\hline Gooseflesh & $0.4(0.2)$ & $0.5(0.3)$ & $0.4(0.2)$ & NS \\
\hline Sweating & $0.4(0.2)$ & $0.6(0.7)$ & $-0.1(0.2)$ & NS \\
\hline Subject rated VAS & $29.8(5.8)$ & $27.5(7.1)$ & $25.5(4.5)$ & NS \\
\hline \multicolumn{5}{|l|}{ Vital Signs } \\
\hline $\mathrm{SBP}(\mathrm{mm} \mathrm{Hg})$ & $8.6(3.1)$ & $7.3(3.0)$ & $9.3(4.2)$ & NS \\
\hline $\mathrm{DBP}(\mathrm{mm} \mathrm{Hg})$ & $7.0(1.3)$ & $7.7(1.3)$ & $7.0(2.8)$ & NS \\
\hline Pulse $(/ \min )$ & $4.6(3.7)$ & $3.8(2.7)$ & $1.1(2.0)$ & NS \\
\hline Respiration (/min) & $-1.4(1.2)$ & $-0.3(0.4)$ & $-0.9(0.7)$ & NS \\
\hline Skin $\left({ }^{\circ} \mathrm{F}\right)$ & $-3.3(1.3)$ & $-3.6(1.0)$ & $-2.6(1.4)$ & NS \\
\hline \multicolumn{5}{|l|}{ Eye } \\
\hline Pupil photo size $(\mathrm{mm})^{b}$ & $1.1(0.3)$ & $1.8(0.3)$ & $1.6(0.4)$ & NS \\
\hline
\end{tabular}

Bold, value differs from placebo in planned comparison. Italic, placebo change values are significantly $(p<$ .05 , two-tailed) different from zero, reflecting a nonzero change from baseline after naloxone. ${ }^{a} F($ df 2,12$)=4.7, p<.04$.

${ }^{b} \mathrm{~N}=6$ for full ANOVA because of subject missing pupil photos for placebo GHB challenge.

Italic, placebo change values are significantly ( $\mathrm{p}<.05$, two-tailed) different from zero, reflecting a non/ zero change from baseline after naloxone. 


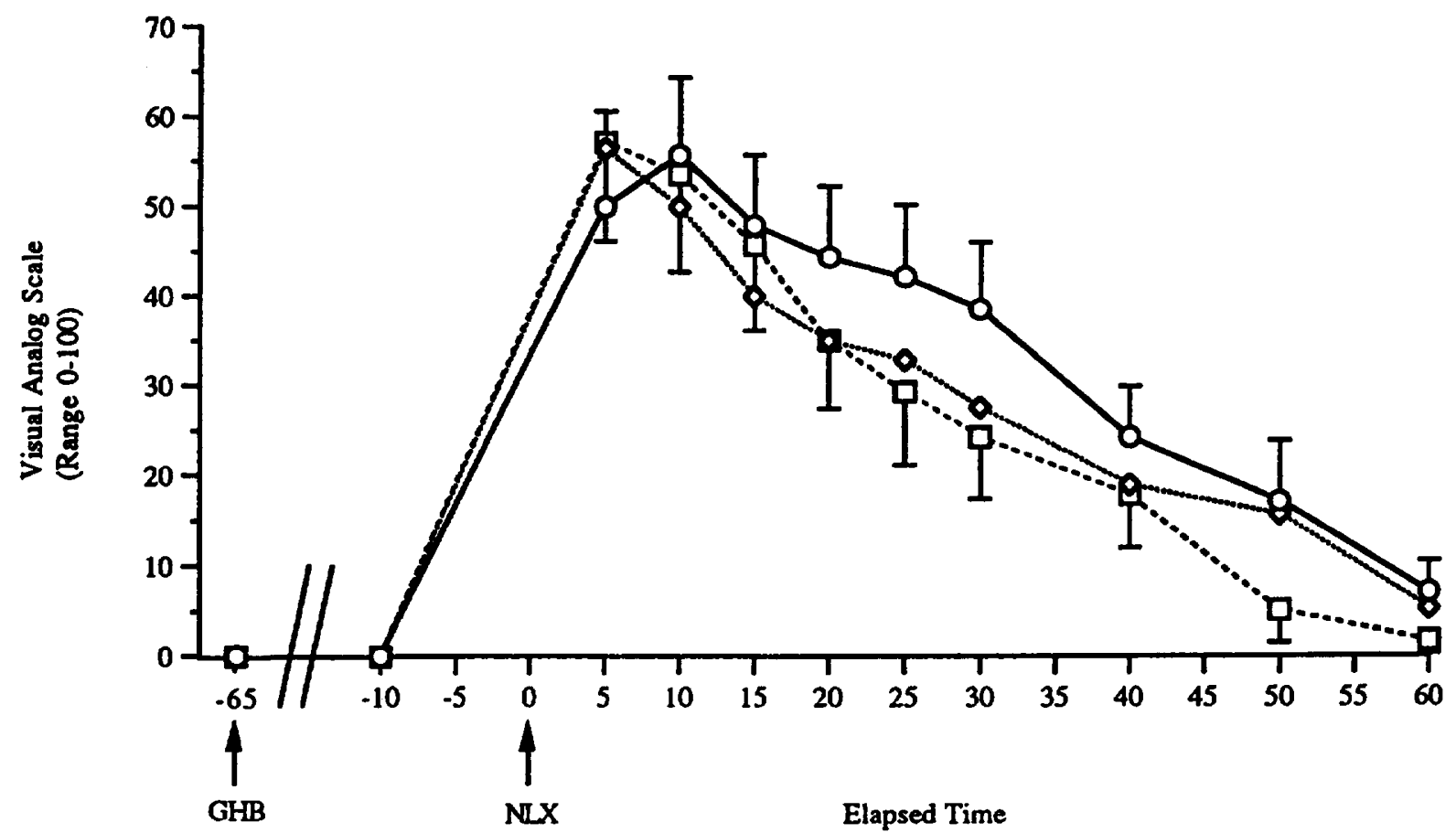

Figure 1. Mean ( \pm SEM) subject-rated withdrawal over time by GHB condition $(n=7)(-\ominus-$ placebo, $\cdots \diamond \cdots 15 \mathrm{mg}$ GBH, - $-30 \mathrm{mg} \mathrm{GHB})$.

ceding 5 minutes (e.g., counts of yawns, muscle stretches, etc.) yield AUC-change/minute scores five times the number of occurrences/minute. The two summary values (baseline difference and AUC-change/time) were analyzed in a one-factor (GHB dose) repeated measures analysis of variance (ANOVA) with planned comparisons at each active GHB dose to placebo. Univariate analyses and the Huynh-Feldt correction for departure from sphericity were used. All $F$ ratios with $p$ values less than .05 (two-tailed) were noted as significant. One subject did not receive naloxone after $\mathrm{GHB}, 15 \mathrm{mg} / \mathrm{kg}$, because of lack of intravenous access; this subject is not included in the full ANOVA of AUC change/time or in graphs of withdrawal measures over time but is included in the planned comparison of placebo and $30 \mathrm{mg}$. One subject's pupil photo size data were not obtained in the GHB placebo challenge. Another subject's skin temperature could not be collected in any challenge because of equipment failure.

\section{RESULTS}

\section{Effects of GHB prior to Naloxone}

The only baseline difference score to vary across GHB conditions was respirations. Respirations decreased a mean of 2.1 breaths/per minutes $( \pm 1.1)$ in the placebo from the 30-mg dose (mean $=0$ ) and there was no significant difference from placebo. The subjects were not in withdrawal prior to GHB administration, and baseline difference scores were the same across GHB conditions.

\section{Effects of GHB on Opiate Withdrawal: Physiological Signs}

The AUC change in withdrawal values with placebo GHB pretreatment was robust and in the expected directions. Table 1 indicates the AUC change (divided by 60 minutes) of $8.6 \mathrm{mmHg} /$ minute in SBP, $7.0 \mathrm{mmHg} /$ minute in DBP, $4.6 \mathrm{bpm}$ in pulse, and $1.1 \mathrm{~mm} / \mathrm{minute}$ in pupil photo size. As expected, skin temperature decreased an average of $2.5^{\circ} /$ minute. None of these changes were altered by GHB administration.

\section{Effects of GHB on Opiate Withdrawal: Behavioral Signs}

As indicated in Figures 1 and 2, substantial subjective and observer-rated withdrawal was elicited by naloxone administration. Table 1 includes the 12 symptoms that comprise "withdrawal" in Figure 2. The only significant main effect of GHB on any measure of withdrawal severity was attenuation of "hot/cold," which was 


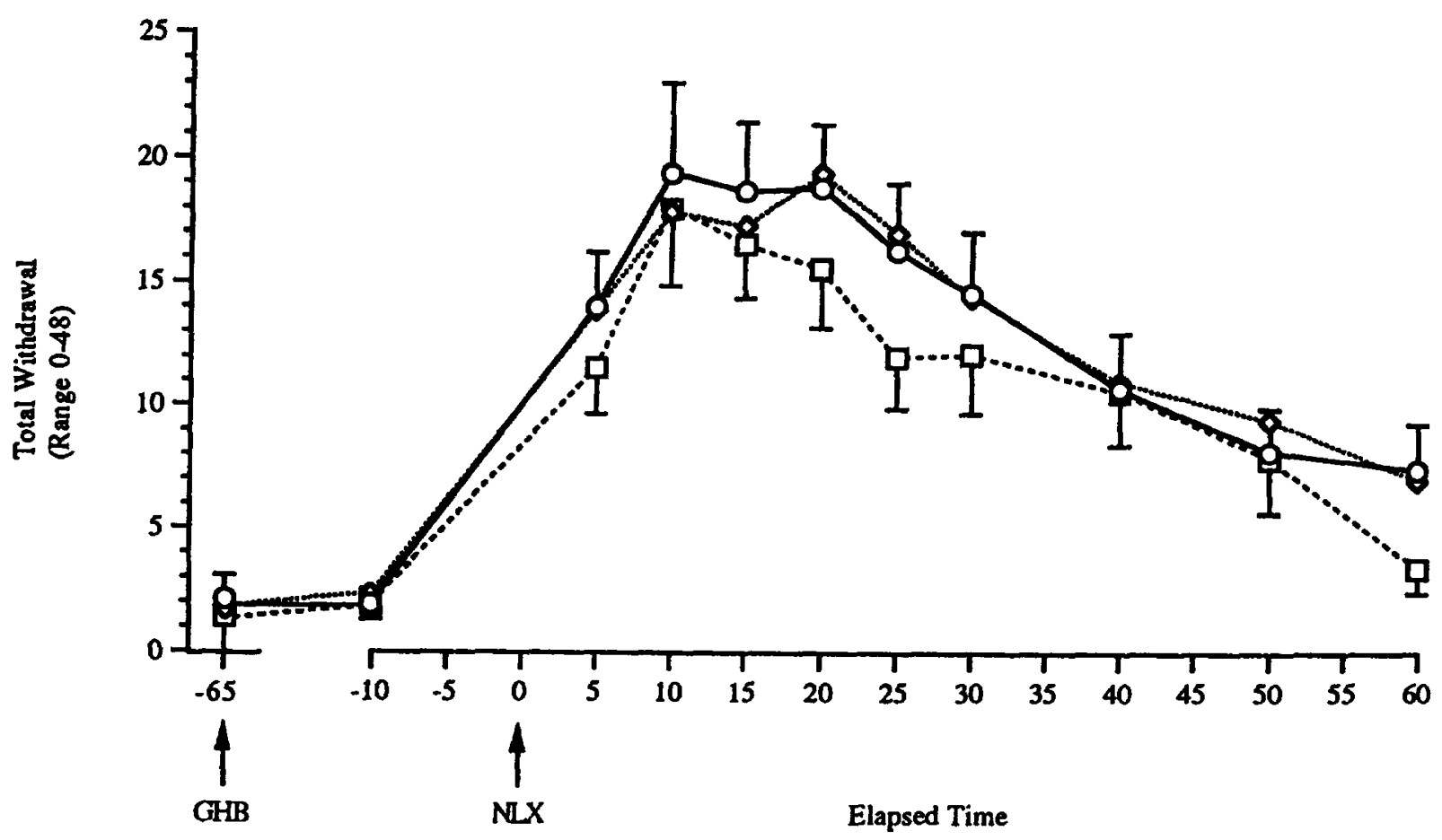

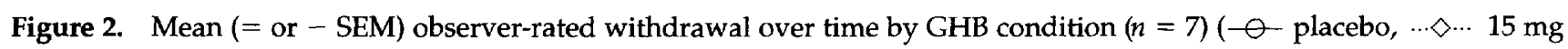
GHB, - $\square \cdot 30 \mathrm{mg} \mathrm{GHB})$.

less subject-rated withdrawal with active GHB $[F(\mathrm{df} 2$, $12)=0.4$, nonsignificant]

\section{DISCUSSION}

The main finding of this study was that GHB had minimal effects on naloxone-precipitated opiate withdrawal. These results were consistent across a number of withdrawal measures. Possible explanations for the difference from findings in spontaneous withdrawal include (1) differences in timing of GHB administration (given postwithdrawal in prior studies); (2) the fact that naloxone may directly reverse GHB's anti-withdrawal effects; or (3) behavioral or neurochemical differences between naloxone-precipitated and spontaneous opiate withdrawal.

A sample size of seven in the full ANOVA would be sufficient to detect an effect size $(F)$ of 0.7 with a power of .08 [alpha $=.05$, two-tailed (Cohen 1988)]. There is little evidence of a trend toward GHB attenuation in our data. Several of the measures shown in Table 1 are precise, long-recognized measures of opiate withdrawal. Table 1 indicates robust withdrawal measured by these indicators and weak or no attenuation by GHB. For example, the mean AUC change of 2.9 yawns (e.g., an increase of roughly 2.9 yawns were counted every five minutes $\times 12$ five-minute intervals $=33$ yawns in 60 minutes) was not significantly altered by GHB pretreat- ment. Our group has demonstrated attenuation of naloxone-precipitated opiate withdrawal signs in seven subjects by pretreatment with the alpha- 2 antagonist clonidine (Rosen et al. in press). Specific signs attenuated included pulse, systolic blood pressure, skin temperature, tearing, and nasal congestion.

The difference between these results and those of Gallimberti et al. (1993) may be affected by the timing of GHB administration in the two studies. Gold et al. (1980) tested clonidine's anti-withdrawal efficacy after methadone discontinuation, using a paradigm similar to that of Gallimberti et al. (1993). Gold et al. reported far greater subjective relief of withdrawal symptoms than studies that used clonidine to prevent withdrawal (Jasinski et al. 1985). A study comparing placebo to dynorphin given after the onset of withdrawal in opiate addicts found that placebo effected an approximately $20 \%$ reduction of subject-rated withdrawal and somewhat less attenuation of observer-rated withdrawal (Wen and Ho 1982). It is possible that some of the categorical measures (present or absent) of withdrawal signs in the Gallimberti study of spontaneous withdrawal may have been influenced by subjective relief at getting active medication.

An across-study comparison of the untreated withdrawal severity in the Gallimberti study and in our study suggests that there were equal or higher reported frequencies of most withdrawal signs in the Gallimberti study than in ours. Gallimberti et al. (1993) reported that post discontinuation of methadone $(n=13)$ or her- 
oin $(n=14)$ and prior to GHB administration, $80 \%$ or more or of the subjects had each of the following: nausea, anxiety/restlessness, aching muscles or bones, yawning, tachycardia, and increased blood pressure. Hot and cold flashes were noted in $74 \%$ of subjects, gooseflesh in $71 \%$, and vomiting in $18 \%$. By way of comparison, the percentages for our subjects withdrawal after placebo GHB pretreatment were $100 \%$ demonstrating hot and cold flashes, $38 \%$ having gooseflesh, and none vomiting. However, the time courses of withdrawal in the two studies were different, with a much more rapid, acuteonset withdrawal after naloxone administration than after opioid discontinuation.

One possible explanation for GHB's nonattenuation of naloxone-precipitated opiate withdrawal is that GHB's effects may be mediated by opiate receptors that are blocked by naloxone. High doses of naloxone have been reported to reverse GHB's EEG (Snead and Bearden 1980) and cerebral metabolic effects in the rat (Crosby et al. 1983), although naloxone does not reverse GHB-induced sleep or striatal dopamine changes in mice (Devoto et al. 1994). It is unlikely that GHB acts through mu opiate receptors, as GHB does not cause analgesia (Sherman and Gebhart 1975) or significant pupillary constriction at lower doses [ $<50 \mathrm{mg} / \mathrm{kg}$ (Metcalf et al. 1966)] as mu opiates do. Our results suggest that GHB did not produce mu opioid effects, as pupil photo size was numerically the same $(7.4 \mathrm{~mm})$ before and after the $30-\mathrm{mg} / \mathrm{kg}$ GHB dose. In fact, there was a nonsignificant trend toward larger pupil photo size changes post naloxone after 30 $\mathrm{mg} / \mathrm{kg}$ of GHB compared with placebo [Table 1; $F$ (df$1,5)=4.8 ; p=.08)]$. The slightly increased respiration rate after the $15-\mathrm{mg} / \mathrm{kg}$ GHB dose (before naloxone) does not suggest mu activity either. Alternatively, it is possible that GHB could attenuate spontaneous opiate withdrawal by stimulating release of endogenous kappa agonists and that naloxone's binding to kappa receptors reverse these effects. One investigator has implicated kappa (Snead 1987) and delta (Snead and Bearden 1982) opioids in inducing epileptiform activity and noted the reversal of GHB-induced seizures by naloxone. A microdialysis study suggests that GHB enhances release of opioidlike substances in the striatum (Hechler et al. 1991).

Our study did not demonstrate an effect of GHB on any aspect of naloxone-precipitated opiate withdrawal except for hot and cold feelings. A controlled study of GHB in clinical detoxification would be necessary to answer definitively the question of GHB's clinical antiwithdrawal efficacy.

\section{ACKNOWLEDGMENT}

This study was supported by NIDA grants K20DA00191-01 (MIR), K02-DA00112 (TRK), 1P01-DA08227, R18-DA06190,
P50-DA04060. We also wish to acknowledge the technical support of Rhonda Pruzinsky.

\section{REFERENCES}

Aldrete JA, Barnes DP (1968): 4-hydroxybutyrate anaesthesia for cardiovascular surgery. Anaesthesia 23(4):558-565

Benavides J, Rumigny JF, Bourguignon JJ, Case C, Wermuth CG, Mandel P, Vincendon G, Maitre M (1982): High affinity binding site for gamma-hydroxybutyric acid in rat brain. Life Sci 30:953-961

Blumenfeld M, Suntay RG, Harmel MH (1962): Sodium gamma-hydroxybutyric acid: A new anesthetic adjuvant. Anesthes Analges Cur Res 41(6):721-726

Centers for Disease Control (1991): Multistate outbreak of poisonings associated with illicit use of gamma hydroxybutyrate. JAMA 265(4):447-448

Cohen J (1988): Statistical Power Analysis for the Behavioral Sciences, ed 2. Hillsdale, NY, Erlbaum

Crosby G, Ito E, Kaufman E, Nelson T, Sokoloff L (1983): Naloxone pre-treatment alters the local cerebral metabolic effect of gamma-hydroxybutyrate in rats. Brain Res 275:194-197.

Devoto P, Colombo G, Cappai F, Gessa L (1994): Naloxone antagonizes ethanol- but not gamma-hydroxybutyrateinduced sleep in mice. Eur J Pharmacol 252:321-324

Doherty JD, Hattox SE, Snead OC, Roth RH (1978): Identification of endogenous and gamma-hydroxybutyrate in human and bovine brain and its regional distribution in human, guinea pig, and rhesus monkey brain. J Pharmacol Exp Ther 207:130-139

Engberg G, Nissbrandt H (1993): Gamma-hydroxybutyric acid (GHBA) induces pacemaker activity and inhibition of substantia nigra dopamine neurons by activating GABA $_{B}$-receptors. Arch Pharmacol 348:(5):491-497

Gallimberti L, Canton G, Gentile N, Ferri M, Cibin M, Fadda F, Ferrara SD, Gessa GH (1989): Gamma-hydroxybutyric acid for treatment of alcohol withdrawal syndrome. Lancet (II):787-789

Gallimberti L, Cibin M, Pagnin P, Sabbion R, Pani PP, Pirastu R, Ferrara SD, Gessa GL (1993): Gamma-hydroxybutyric acid for treatment of opiate withdrawal syndrome. Neuropsychopharmacol 9(1):77-81

Gold MS, Pottash AC, Sweeney DR, Kleber HD (1980): Opiate withdrawal using clonidine. JAMA 243(4)343-346

Hechler V, Gobaille S, Bourguignon JJ, Maitre M (1991): Extra cellular events induced by gamma-hydroxybutyrate in striatum: A microdialysis study. J Neurochem 56:938-944

Hechler V, Peter P, Gobaille S, Bourguignon J, Schmitt M, Ehrhardt J, Mark J, Maitre M (1993): Gamma-hydroxybutyrate ligands possess antidopaminergic and neuroleptic-like activities. J Pharmacol Exp Ther 264(3):1406-1414

Isbell H, Fraser HF (1953): Actions and addiction liabilities of dromoran derivatives in man. J Pharmacol Exp Ther 107:524-530

Jaffe JH, Martin WR (1985): Opioid analgesics and antagonists. In Gillman AG, Goodman LS, Rall TW, Murad F 
(eds), The Pharmacological Basis of Therapeutics, ed 7, New York: Macmillan

Jasinski DR, Johnson RE, Kocher TR (1985): Clonidine in morphine withdrawal: Differential effects on signs and symptoms. Arch Gen Psychiatry 42:1063-1066

Kosten TR, Rounsaville BJ, Kleber HD (1985): Comparison of clinician ratings to self reports of withdrawal during clonidine detoxification of opiate addicts. Am J Drug Alcohol Abuse 11(1-2):1-10

Mack RB (1993): Love potion number 8 (one-half sign): Gamma-hydroxybutyrate poisoning. North Carolina Med J 54(5):232-233

Maitre M, Rumigny JF, Cash CD, Mandel P (1983): Subcellular distribution of gamma-hydroxybutyrate bindings sites in rat brain: principal localization in the synaptosomal fraction. Biochem Biophys Res Com 110(1):262-265

Mamelak M, Scharf MB, Woods M (1986): Treatment of narcolepsy with gamma-hydroxybutyrate: A review of clinical and sleep laboratory findings. Sleep 9(1):285-289

Metcalf DR, Emde RN, Stripe JT (1966): An EEG-behavioral study of sodium hydroxybutyrate in humans. Electroenceph Clin Neurophysiol 20:506-512

Nelson T, Kaufman E, Kline J, Sokoloff L (1981): The extraneuronal distribution of gamma-hydroxybutyrate. J Neurochem 37:1345-1348

Papavasiliou PS, Cotzias GC, Mena I, Bell M (1973): Oxybate sodium for parkinsonism. JAMA 224(1):130

Peachey JE, Lei H (1988): Assessment of opiate dependence with naloxone. Br J Addictions 83:193-201

Rosen MI, McMahon TH, Hameedi F, Pearsall HR, Woods SW, Kreek MJ, Kosten TR (in press): The effect of clonidine pre-treatment on naloxone-precipitated opiate withdrawal. J Pharmacol Exp Ther

Rosen MI, McMahon TJ, Margolin A, Gill TS, Woods SW,
Pearsall HR, Kreek MJ, Kosten TR (1995): Reliability of sequential naloxone challenge test. Am J Drug Alcohol Abuse 21(4):453-467

Rudd P, Blaschke TF (1985): Antihypertensive agents and the drug therapy of hypertension. In Gillman AG, Goodman LS, Rall TW, Murad F (eds), The Pharmacological Basis of Therapeutics, ed 7, New York: Macmillan

Schmidt C, Gobaille S, Hechler V, Schmidt M, Bourguignon JJ, Maitre M (1991): Anti-sedative and anti-cataleptic properties of NCS-382, a gamma-hydroxybutyrate receptor antagonist. Eur J Pharmacol 203:393-397

Sherman AD, Gebhart GF (1975): An evaluation of the analgesia induced by morphine and gamma-hydroxybutyrate. Arch Int Pharmacodyn 213:195-199

Snead OC (1977): Minireview: Gamma hydroxybutyrate. Life Sci 20:1935-1944.

Snead OC (1987): Opioid peptides and seizures. Rev Clin Basic Pharmacol 6:329-330

Snead OC, Bearden LJ (1980): Naloxone overcomes the dopaminergic, EEG, and behavioral effects of gamma-hydroxybutyrate. Neurology 30:832-838

Snead OC, Bearden LJ (1982): The epileptogenic spectrum of opiate agonists. Neuropharmacol 21:1137-1144

Tunnicliff G (1992): Significance of gamma-hydroxybutyric acid in the brain. Gen Pharmacol 23(6):1027-1034

Walters JR, Roth RH (1972): Effect of gamma-hydroxybutyrate on dopamine metabolites in the rat striatum. Biochem Pharmacol 21:2111-2121

Wen HL, Ho WK (1982): Suppression of withdrawal symptoms by dynorphin in heroin addicts. Eur J Pharmacol 82:183-186

Wilkinson P (1994): The young and the reckless. Rolling Stone Magazine 5(681):29-30 